\title{
The Extravehicular Maneuvering Unit's New Long Life Battery and Lithium Ion Battery Charger
}

\author{
Samuel P. Russell ${ }^{1}$ and Mark A. Elder ${ }^{2}$ \\ NASA Johnson Space Center, Houston, Texas \\ Antony G. Williams ${ }^{3}$ \\ Jacobs Engineering, Houston, Texas \\ Jacob Dembeck ${ }^{4}$ \\ ABSL, Inc, Longmont, Colorado
}

\begin{abstract}
The Long Life (Lithium Ion) Battery is designed to replace the current Extravehicular Mobility Unit Silver/Zinc Increased Capacity Battery, which is used to provide power to the Primary Life Support Subsystem during Extravehicular Activities. The Charger is designed to charge, discharge, and condition the battery either in a charger-strapped configuration or in a suit-mounted configuration. This paper will provide an overview of the capabilities and systems engineering development approach for both the battery and the charger.
\end{abstract}

\section{Introduction}

$\mathrm{T}$ he Long Life (Lithium Ion) Battery (LLB) is designed to replace the current Extravehicular Mobility Unit (EMU) Silver/Zinc (Ag/Zn) Increased Capacity Battery (ICB), which is used to provide power to the Primary Life Support Subsystem (PLSS) during Extravehicular Activities (EVAs). The resulting system includes a long-life rechargeable battery, a portable Intravehicular Activity (IVA) charger which includes a softgoods bag for cable and fuse storage.

This paper discusses the new battery/charger system to include the replacement rationale, operations concept, battery and charger design, and the screening methods employed to ensure a highly reliable and safe product was delivered for use in a critical human spaceflight application. This paper only addresses the latest design iteration of the lithium ion battery intended for EMU application and as such begins with a relatively high technology readiness level. Development of this readiness level is summarized herein.

\section{Replacement Rationale}

The ICB was a second generation battery. While an improvement of the prior, baseline, battery, the ICB still presented challenges and limitations. For example, the ICB was certified for a 300 day lifetime, with not more than 12 charger/recharge cycles. Given the planned retirement of the Space Shuttle, NASA's ability to return payloads to Earth for refurbishment would be significantly reduced, causing the ICB lifetime to be a concern.

While launch costs are the principle driver for a long-life, reusable battery design, continued reliance on the ICB presents several operational limitations which must be accommodated by crew time planners and on-orbit personnel including: a required $4 \mathrm{hr}$ rest period between charge and discharge operations, a 10\% permanent capacity loss if charge is interrupted, and strict adherence to a maintenance cycle every 85 days. Additional logistic burden is

\footnotetext{
${ }^{1}$ Project Manager, Energy Systems Division, 2101 NASA Parkway, Houston, TX 77058

${ }^{2}$ Project Manager, Extra-Vehicular Activities Office, , 2101 NASA Parkway, Houston, TX 77058

${ }^{3}$ Chief Engineer, Science, Engineering, and Analysis Services Department, 2224 Bay Area Blvd, Houston, TX 77058, Associate Fellow

${ }^{4}$ Project Engineer, 2602 Clover Basin, Ste D, Longmont, CO 80503
} 
placed on the ISS Program in the post-Space Transportation System (Shuttle) era as the ICB is delivered to the launch site dry and requires a 40-day activation and formation prior to launch. Since the ICB utilizes an aqueous electrolyte and a spring-load relief device, once formation is complete (a necessary ground process based on current on-orbit capability), the ICB is orientation sensitive and cannot be launched upside down. Finally, the ICB flat discharge profile shown in Figure 1 makes state of charge indication difficult, a challenge for decision making by ground operators during performance of an EVA.

\section{CONOPS}

Onboard the International Space Station (ISS), the EMU LLB and LIB Charger provides reusable power for the Extravehicular Mobility Unit (EMU). The EMU allows astronauts the ability to conduct EVAs. The operational concept for the LLB and LIB Charger is as a stand-alone system which is stored until required for EVA. During preparation for EVA, the ISS crew will extract the LIB Charger and necessary cabling from Crew Transfer Bag storage, connect the LIB Charger to 120Vdc (or 28Vdc auxiliary power) and connect each charger channel to a battery, which can be attached to the charger via a Velcro strap, or installed in the EMU planned for use. Connection to the EMU-installed battery is achieved by unzipping the Thermal Micrometeoroid Garment to expose the charge connector on the LLB and connecting the charge cable. Once charge completion indication is verified, the charge cables are disconnected and the TMG closed. At the end of the EVA, the battery can either be serviced for repeat EVA or discharged to below 50\% State of Charge (SOC) to enable stowage in the EMU. Batteries which are not used within one calendar year are subjected to an annual maintenance cycle requirement consisting of an autocycle and verification that battery capacity exceeds the minimum requirement for EVA. Fault detection is built into the LIB Charger and the use of flight certified data logging software enables recording of LIB Charger and LLB performance characteristics during charge/discharge operations for trouble shooting by ground analysis.

The interfaces for the LLB-LIB Charger system are shown in Figure 2.

The following assumptions were made in development of the LLB system to support mission planning and certification:

- Typical EVA duration is foursix hours although eight hour capability is desired

- A minimum of four LLBs will be stored onboard ISS although once on-orbit performance has been demonstrated, this number may be reduced to three if necessary (two suits with one spare)

- The battery must support EVA operations in a number of possible scenarios, including the following (EVA Office, 2003):

Nominal usage
consisting of four
charge/rest/discharge

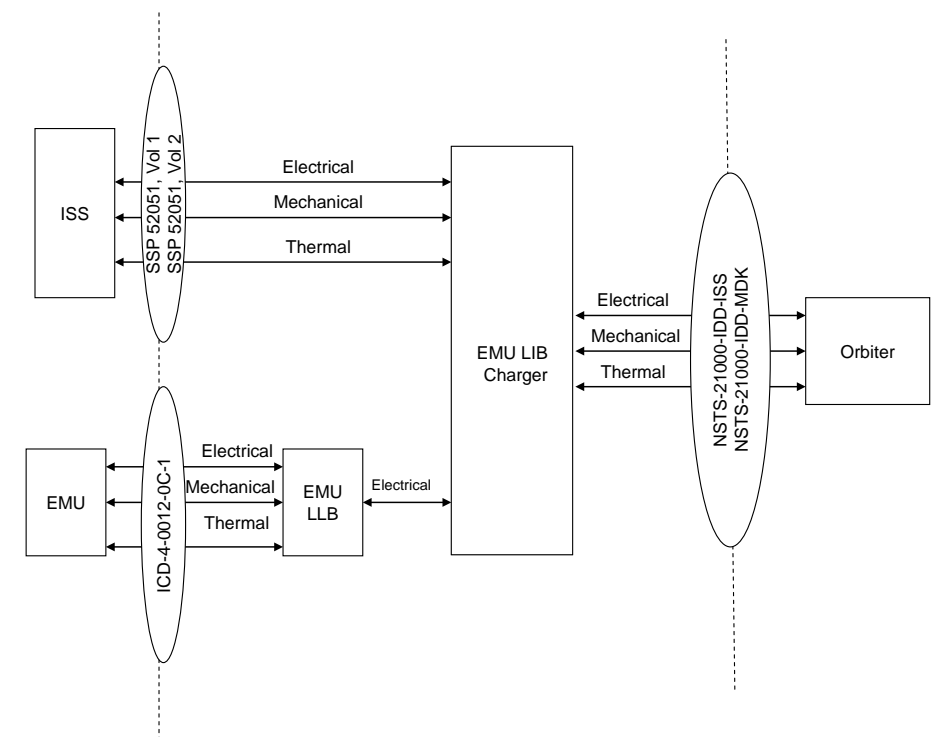

Figure 2 - LLB-LIB Charger System Interface Definition

American Institute of Aeronautics and Astronautics 
cycles evenly spaced throughout the year.

o Maximum usage consisting of 30 charge/rest/discharge cycles evenly spaced throughout the year (the even spacing simulates a worse case condition).

o Minimum usage consisting of two charge/rest/discharge cycles evenly spaced throughout the year.

0 Off-nominal usage consisting of five EVAs performed in five consecutive days using two batteries on alternating days (This usage results in three consecutive 48-hour charge-discharge cycles of the battery design and was specified to support missions such as the Hubble Space Telescope Repair).

Launch rates for the EMU LLB system are dependent on the retirement date for the Space Shuttle and demonstration of on-orbit performance. As currently planned, the shuttle will retire at the end of 2010 after delivering the initial manifest of four batteries, two chargers and two accessory pouches and any parts needing future replacement will launch primarily on expendable launch vehicles. Based on this plan, each EMU LLB and charger will launch only a single time on a delivery mission to the ISS. Once the delivered chargers or batteries are deemed no longer viable on-orbit assets, they will be disposed during return of a single-use ISS Partner cargo resupply vehicle such as the Russian Progress, European Automated Transfer Vehicle, Japanese H-II Transfer Vehicle, or Commercial return vehicle. Replacement units are certified for single launch on any of the ISS Program partner vehicles in the soft-stowed configuration. Should immediate return be required, the battery and charger are certified for one round-trip on the STS Shuttle and a single launch on an ISS Program partner vehicle.

The EMU LIB charger charges, discharges, and tests the LLB. The EMU LIB charger is an electronics box which contains two identical and independent charger channels capable of independent or simultaneous charging of one or two LLBs off of a single power source. Even though the EMU LIB charger can be powered and used upon the Space Shuttle Orbiter, it will primarily be powered by and used on the ISS. The charger is designed for IntraVehicular Activity (IVA) use only. The Charger is portable and may be fastened to shuttle or ISS structure with hook and loop fasteners. The Charger also contains a hook-and-loop fastened strap for attachment of up to two LLBs for out-of-suit charging or maintenance/troubleshooting operation. The Charger is powered through existing connector outlets provided by the Space Transportation System (STS) or ISS vehicles. As the ISS and STS use different power systems and maintain unique connector configuration requirements, the LIB Charger utilizes separate connectors for each input power voltage. The LIB Charger is designed for a 15 year life and requires fiveyear calibration verification. LIB Charger operational and control parameters are not user configurable on-orbit, so if calibration verification indicates performance deviation has occurred, the problem must be addressed by ground crew operational protocol or the unit replaced.

The EMU LIB Charger also includes two soft cable/fuse accessory kits, a primary and a secondary pouch. The primary kit contains the accessories required for nominal operation on 120Vdc power, long charge cables for in-suit charging, short charge cables for battery servicing/troubleshooting, USB data cables for connection to a Space Station Computer (SSC) should data recording be required, and spare fuses for the LIB Charger. The secondary pouch contains $28 \mathrm{Vdc}$ power cables, extra long and short charge cables, an extra USB data cable, additional fuses including the replaceable LLB fuse, and is scarred for future flight of the calibration verification cable.

The existing on-orbit charger used for the ICB is incapable of charging the LLB without the use of an adaptor due to physical interface with the Battery Service Adaptor. Physical interference may seem an issue, but the difference in hazard control methodology between the two battery-charger systems necessitates the conflict. The LLB system was designed for high reliability to preserve EVA functionality necessitating integration of hazard control logic into the charger and thereby minimizing battery complexity. As a result of this architectural decision, the LIB Charger complexity necessarily increased while the battery complexity remained minimal. An adaptive component with the proper hazard controls to enable use of the on-orbit charger is under development in the event an unforeseen systemic LIB Charger failure should become evident and redundant charging method become necessary. The adaptive device is not included herein due to design and certification immaturity.

\section{Key Performance Targets}

The LLB was designed to fit within the physical and interface constraints of the EMU and ICB, and meet EVA, shelf life and cycle life performance requirements. In addition to the cost benefit of improved service life cycle, the LLB enhances long-term ISS mission flexibility. In the post-Shuttle era, when no STS-based EVAs are planned, a battery which retains capability, requires minimal routine servicing and minimal crew involvement enables rapid 
response should quick readiness for EVA be required. The top-level system performance requirements are shown in Table 1.

\begin{tabular}{l|c} 
Table 1 Key Performance Parameters for LLB and ICB \\
REQUIREMENT & LLB
\end{tabular}

NOTE

\begin{tabular}{|c|c|c|c|}
\hline $\begin{array}{l}\text { Capacity at End-of-Life } \\
\text { (EOL) }\end{array}$ & 26.6 Ahr & 26.6 Ahr & $\begin{array}{l}\text { 3.8A discharge with } \\
\text { 9A, 5s start-up pulse }\end{array}$ \\
\hline $\begin{array}{l}\text { Open Circuit Voltage } \\
\text { (OCV) }\end{array}$ & $16-21 \mathrm{~V}$ & $16-21 \mathrm{~V}$ & $\begin{array}{l}\text { EMU cooling fan } \\
\text { operates at } 17 \mathrm{Vdc}\end{array}$ \\
\hline Service Life & $\begin{array}{c}1820 \text { days (5 years) } \\
50 \% \text { SOC, } 20^{\circ} \mathrm{C}\end{array}$ & 300 days ( $<1$ year) & N/A \\
\hline Cycle Life & $>50$ Cycles & 32 Cycles & N/A \\
\hline Time at Full Charge & 600 days ( $100 \%$ SOC) & -- & N/A \\
\hline Mass & $7.04 \mathrm{~kg}$ (15.5 lbf) & $6.67 \mathrm{~kg}$ (14.7 lbf) & Maximum \\
\hline Volume & $\begin{array}{c}\text { Do Not Exceed ICB } \\
\text { Envelope }\end{array}$ & -- & Limited by EMU \\
\hline Electrical Connection & EMU and LIB Charger & EMU & N/A \\
\hline Mission Simulation & $\begin{array}{c}100 \mathrm{EVA} \text {, half at } 32^{\circ} \mathrm{C}, \\
\text { half at } 10^{\circ} \mathrm{C}\end{array}$ & -- & $\begin{array}{l}\text { Derived requirement to } \\
\text { demonstrate cycle life } \\
\text { with a scatter factor of } 2\end{array}$ \\
\hline Contingency Charger & $\begin{array}{c}\text { Shuttle Air Lock Power } \\
\text { Supply }\end{array}$ & -- & $\begin{array}{l}\text { LLB service life } \\
\text { requires manual } \\
\text { termination at } 21 \mathrm{Vdc}\end{array}$ \\
\hline
\end{tabular}

V. System Design

The EMU LLB system is designed to be a fully-autonomous battery charging and servicing system capable of operation in both ISS and Shuttle environments. The intent of the system is to charge a battery for EVA (either in- or out-of the EMU), provide annual maintenance cycling of unused batteries, and provide insight into battery/charger operation for troubleshooting purposes. The self-contained system is depicted in Figure 3 and consists of one charger (with two independent channels), two Long Life Batteries, and one accessories pouch all secured via strapping with hook-and-loop fasteners. The LLB and LIB Charger System is a portable system which provides necessary hazard controls required for safe operation of the commercial-offthe-shelf COTS lithium ion technology in human spaceflight

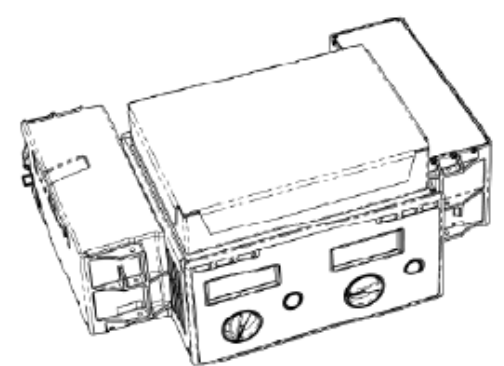

Figure 3. LLB and LIB Charger System application. 


\section{A. Long Life Battery}

The LLB is designed to have the same electrical and mechanical interfaces as the current ICB. The location of the LLB in the EMU is shown in Figure 4 below (battery placement shown on rear view of EMU). The battery latches into the EMU and resides underneath the Thermal Management Garment which shrouds the entire EMU. The EMU is configured to receive power either through the umbilical connector or the in-suit battery, but not both. Due to the EMU power configuration, the LLB is incapable of receiving charge current when the suit is receiving umbilical power. The EMU provides battery operational environment including temperature, electrical load and micrometeoroid protection during EVA but the EMU does not offer protection from the pressure environment or rate of pressurization experienced during EVA.

\section{EXTRAVEHICULAR MOBILITY UNIT}

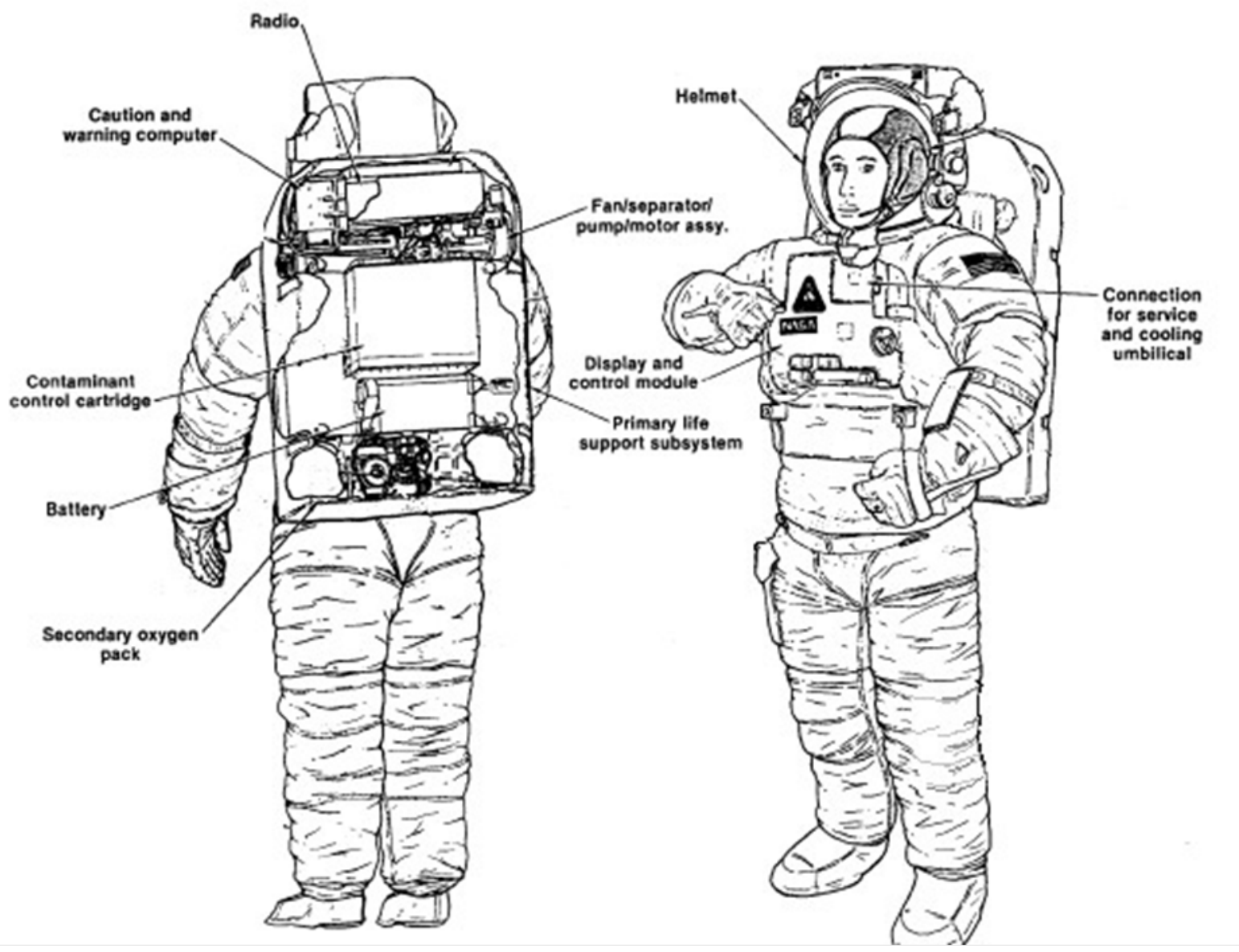

Figure 4. Extravehicular Mobility Unit showing Battery Location

The LLB consists of eighty 18650 (2.4 Ahr) lithium ion electrochemical cells assembled in a 5S 16P configuration composed of five serial banks of 16 parallel cells. The risk of external electrical short is controlled both internally and externally to the battery. The external control is provided by a replaceable fuse dictated by the EMU design. Internal control is required due to the risk of electrically conductive Foreign Object Debris (FOD) making its way into the enclosure as the battery is not designed to be pressurized. Internal electrical short protection is provided by numerous layers of independent Kapton and Nomex insulators located both external to the electrochemical cell arrangement (or brick) as well as between the series banks within the electrochemical cell 
arrange (or battery brick) to prevent shorting between two banks of differing electrical potential. Figure 5 shows the use of both composite Kapton-Nomex-Kapton bank separators and complete external encapsulation of electrically active surfaces with redundant layers of Kapton. Figure 5 shows final brick assembly and configuration drawing while Figure 6 shows the process of final battery assembly according to the graphic of Figure 7. Evident in Figure 7 is the use of adsorptive Nomex paper underneath the enclosure cover to serve as an insulative wicking material should electrolyte leak and escape the battery brick.

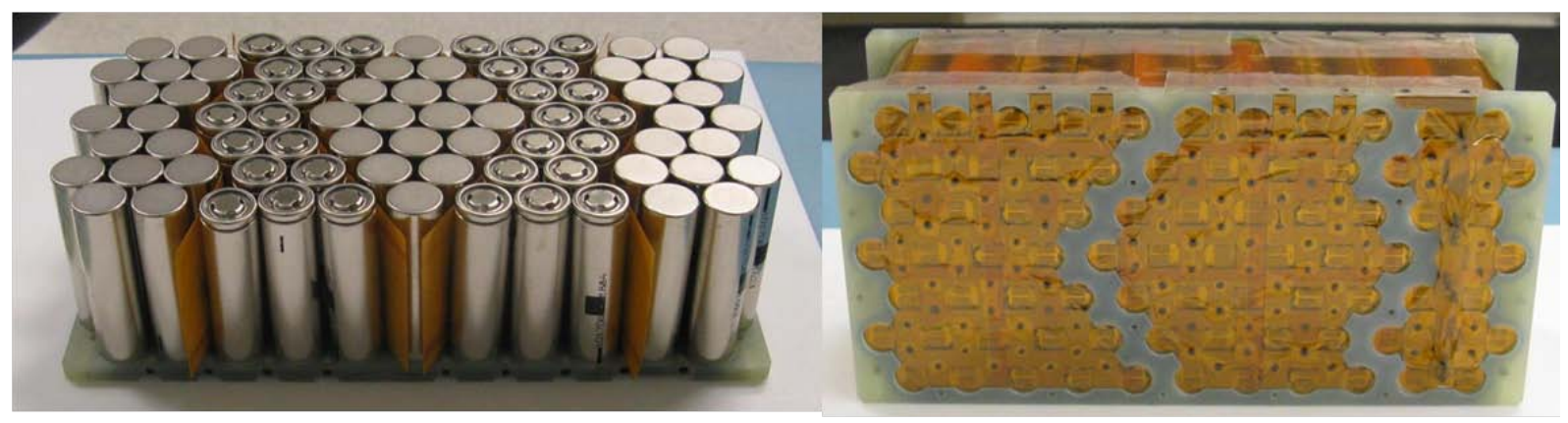

Figure 5. Assembly and Use of Insulator Materials to Reduce External Short Risk
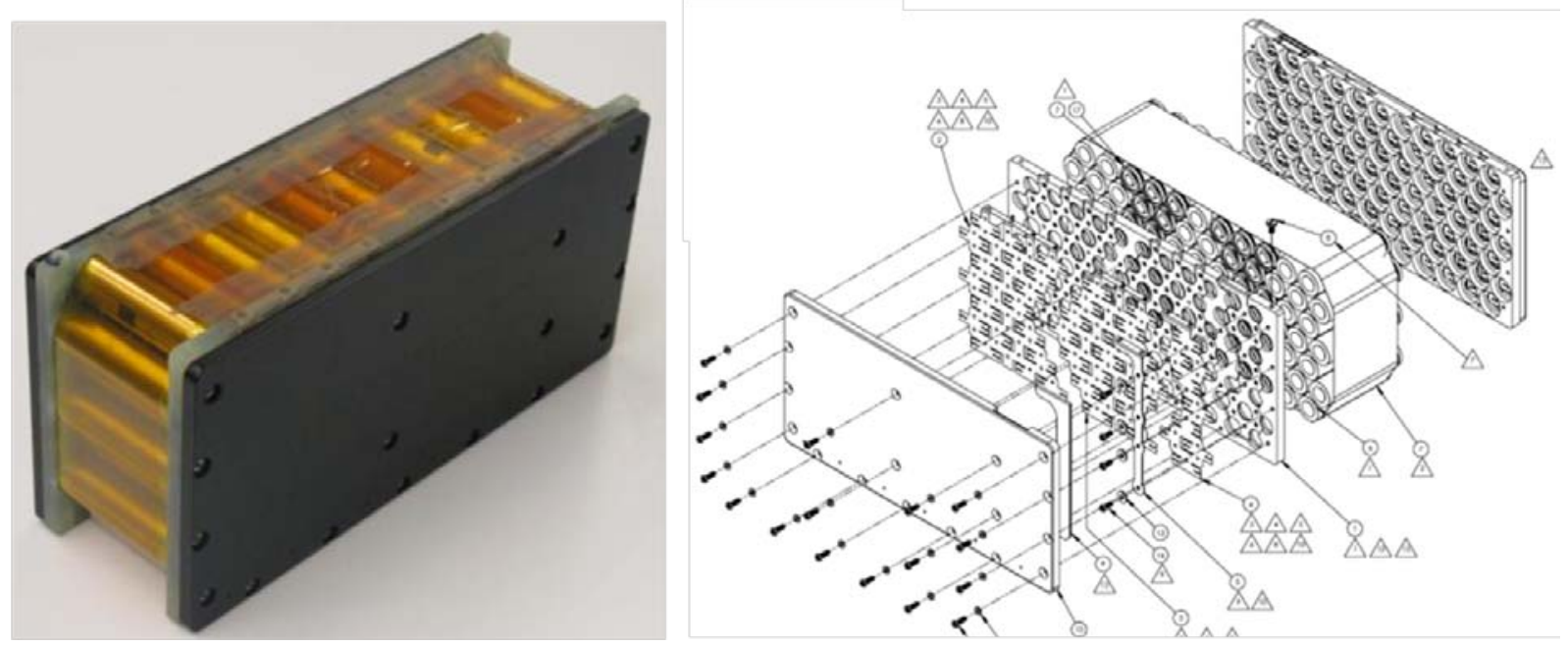

Figure 6. Assembled LLB Brick According to Configuration Drawing

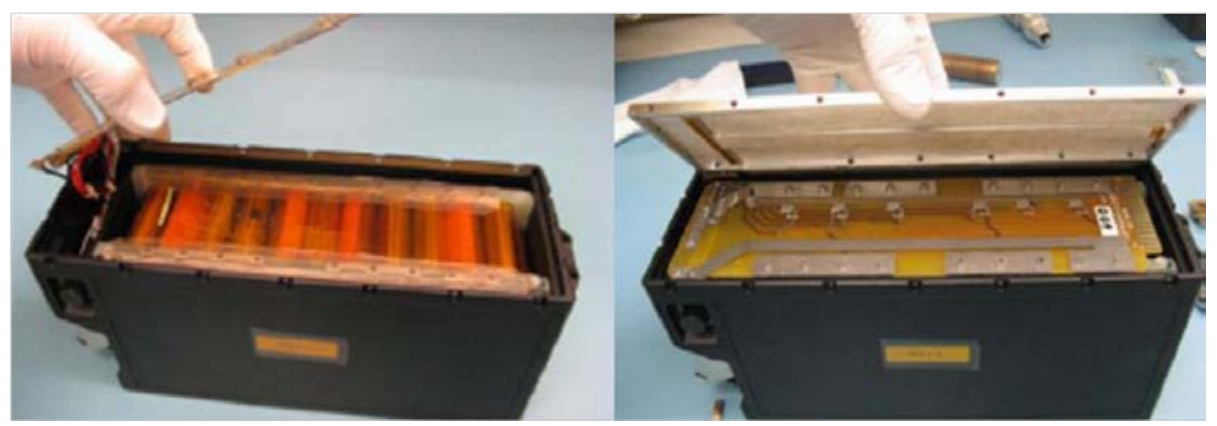

Figure 7. Final Integration into the LLB Configuration

u

American Institute of Aeronautics and Astronautics 


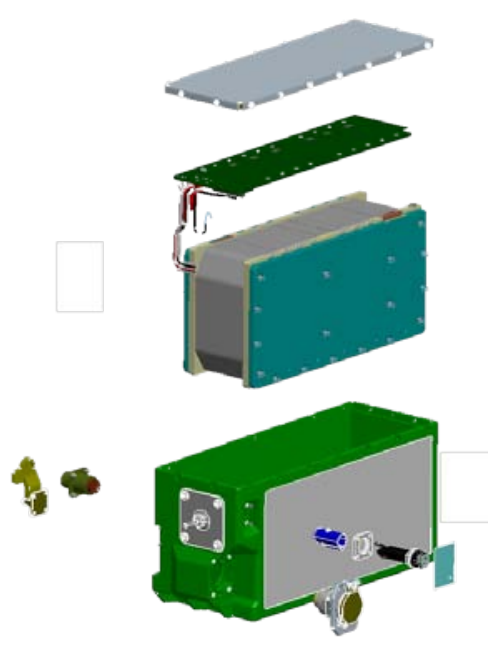

Figure 9. Long Life Battery Assembly

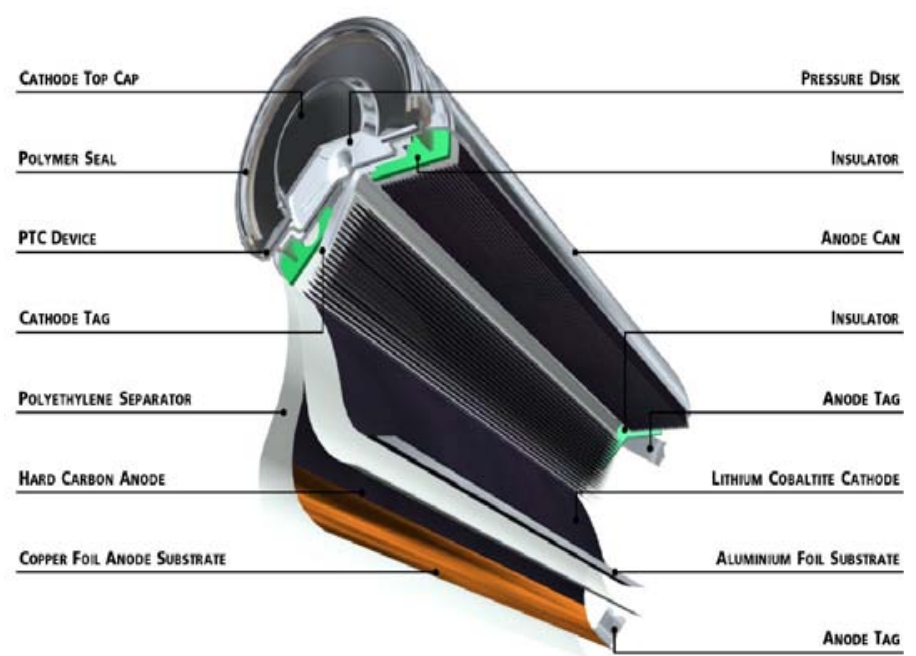

Figure 8. Generic 18650 Lithium Ion Cell Configuration

The LLB design preserved the intended operational environment of the Commercial Off-The-Shelf (COTS) electrochemical cell thus preserving inherent safety features built into the 18650 specification as identified in Figure 8 specifically, the Positive Temperature Coefficient (PTC) device and the Pressure Disk (Current Interrupt Device). Adherence to the 18650 specification was insured through the use of rigorous screening at the cell, battery brick, and battery levels. At each level of build, performance and defect screening was performed to ensure non-compliant subjects were culled from the population. (Note: during this life-time build effort, no bricks or batteries required rejection although cell reject rate neared $15 \%$ mostly due to physical defects such as dents, dings or visible insulator adhesive in the top cap region.) The following screening methods were independently assessed and augmented by a panel of industry and government experts under guidance to the NASA Engineering Safety Center (NESC, 2009) to ensure the upmost of rigor was imposed for this human spaceflight application. Not included herein is the cell lot certification process which consists of a multitude of rigorous capability determination including vent/burst testing, crush testing, Non-Destructive Computed Tomography Evaluation, Destructive Physical Analysis and abuse tolerance capability in the single cell, 16 parallel bank and 80 cell battery configurations.

- Flight COTS cells are rigorously screened to detect manufacturing flaws

o Mass, Open Circuit Voltage (OCV) (after > 24 months storage), AC impedance, visual examination

o Thermal cycling, vacuum cycling with residual gas analysis (leak check)

o Initial charge input (after long storage), capacity performance (2 cycles), DC resistance

o Remove cells with performance variation greater than \pm 3 sigma

o Remove cells designated as marginal performers according to Statistical Reliability Assessment

o $\quad 100 \%$ X-ray examination for proper electrode winding alignment

o Repeat OCV, capacity cycling, AC impedance, DC resistance prior to selecting cells for brick assembly

- Flight 80-cell bricks are rigorously screened to detect manufacturing flaws

o Visual, Mass, OCV, AC impedance, insulation resistance, fit check with housing

o Four vacuum depress/repress cycles with final one holding vacuum for 3 days ( $\&$ at $35^{\circ} \mathrm{C}$ )

o Five thermal cycles with 3 hour dwells at the extremes $\left(-14\right.$ to $\left.45^{\circ} \mathrm{C}\right)$

o Two capacity cycles at room temperature

- one at high rate $(\mathrm{C} / 2$ charge to $21 \mathrm{~V}$ with $1 \mathrm{~A}$ taper, $\mathrm{C} / 2$ discharge to $15 \mathrm{~V})$

- one at mission rate (5A charge to $21.5 \mathrm{~V}$ with $1 \mathrm{~A}$ taper, $3.8 \mathrm{~A}$ discharge to $16 \mathrm{~V}$ )

- Flight LLBs are rigorously screened to detect manufacturing flaws

o OCV, Closed Circuit Voltage (CCV), Thermistor Check, Insulation Resistance, Bonding, Mass, and Visual Inspection 
o Thermal cycling with 3 hourr dwells at the extremes $\left(-14\right.$ to $\left.45^{\circ} \mathrm{C}\right)$

o Random vibration at $0.06 \mathrm{~g}^{2} / \mathrm{Hz}$ for 1 minute/axis ( 0.03 is mission, 0.04 is standard workmanship level)

o 1 hot and 1 cold mission simulation cycle (charge at ambient, discharge at temperature/pressure)

o 1 autocycle (discharge, charge, discharge, recharged to 30\%) with the LIB Charger

\section{B. Charger}

The LIB Charger consists of two independent charge channels and is capable of charging up to two batteries simultaneously from either $120 \mathrm{Vdc}$ or $28 \mathrm{Vdc}$ power (ISS and STS, respectively). The LIB Charger is designed to simplify battery servicing operations such that operation requires minimal setup and ground personnel support. To achieve this autonomy, the LIB Charger is designed to prevent battery mishandling through the use of serial microprocessor control of a power source incapable of over-charging the LLB. The LIB Charger also contains the ability to balance battery bank voltage resulting in a uniform battery capable of delivering maximum capacity. Operational simplicity is offered through the use of $3+1$ functions. The three functions consist of charge (constraint voltage followed by approximated constant current operation), discharge and autocycle. The fourth function is a volts check which delivers to the user closed circuit voltage measurements of the five series banks which make up the LLB as a function of total battery voltage. The autocycle function is a combination of the discharge and charge functions with the final charge cycle terminating with delivery of exactly 10Ahr of charge. The autocycle function provides the user an accurate measurement of battery capacity and prepares the battery for storage. Fault detection operates at various phases in the charge operation according to the principles selected for maintenance of the lithium ion battery. Although in-depth LIB Charger architecture review is not developed herein, a capability summary is offered as follows:

- 2 independent charger channels inside single enclosure

o Capable of servicing 2 EMU LLBs simultaneously and independently while operating inside Shuttle (28Vdc) and ISS (120Vdc) pressurized cabin

- $\quad$ Charge Modes

o $5 \mathrm{~A}$ to $20.6 \mathrm{~V}$ terminating when cell banks OCV reach $4.09 \mathrm{~V}$ during current taper phase (120Vdc)

o $\quad 2.5 \mathrm{~A}$ to $20.6 \mathrm{~V}$ terminating when cell banks OCV reach $4.09 \mathrm{~V}$ during current taper phase (28Vdc)

$0 \quad$ LLB cell bank balancing if needed

- Discharge

o $\sim 1.3 \mathrm{~A}$ to $16.0 \mathrm{~V}$ (or $3.0 \mathrm{~V} /$ cell bank)

- Volts check

o Measures cell bank OCVs

- $\quad$ Autocycle

- Measures battery CCV after 9A, 5s pulse

o Discharges remaining LLB capacity

o Full recharge with cell bank balancing (if needed)

o Full discharge to assess LLB capacity (health)

o $10 \mathrm{Ah}$ recharge to put LLB at $\sim 30 \%$ SoC for storage

- $\quad$ Mode, LLB parameters, and faults are displayed on each channel's LCD and LED

- Designed and built under contract to NASA and redesigned, modified, and fully re-verified by NASA

The LIB Charger achieves autonomy through internal electrical controls resulting in simple and straight-forward user communication via status and fault LED. Additional data is available through a USB port associated with each channel should data logging be required although data recording is not planned for nominal operation. Figure 10 depicts the user interface for a single LIB Charger channel including the mode selection switch, the LCD which displays battery performance, the status LED which delivers mode confirmation as well as charge complete indication and the fault LED which communicate the type of fault experienced. An additional LED indicator is provided to indicate any time the start button has been depressed and a mode is active. This latter indication is in addition to the status LED indication. 


\section{Technology Maturation Assessment}

The Long Life Battery and Lithium Ion Battery Charger project matured a design concept resulting in a system which will deliver rechargeable (and reliable) power to the EMU for the next five to ten years. Using the Technology Readiness Scale adopted by the Department of Defense and NASA, the project element maturity can be assessed for readiness level according to Figure 11 (NASA, 2007). During execution of the effort, the Technology Readiness Level of each element was matured from TRL 4 for the battery, TRL 8 for the LIB Charger and TRL 7 for the LIB Charger data logging software to TRL 8 for each element.

In addition to technology readiness, each project element's Integration Readiness can be assessed using a similar method as shown in Figure 12 (Sauser, Ramirez-Marquez, Verma, \& Gove, 2006). As a result of technology maturation, the Integration Readiness Level advanced from IRL 6 for the battery, IRL 6 for the LIB Charger and IRL 8 for the data logging software to IRL 8 for each system element.

During technology and integration readiness maturation, the risk electrochemical cell internal short was addressed by focus session and Delphi assessment in the following forums as well as commission of a novel electricalkinetic-thermal model developed by the National Renewable Energy Laboratory (Smith, 2010):

- $\quad$ Special conference session attended by government and industry experts and practitioners (Conference Proceedings, 2009)

- Independent review by the NASA Engineering Safety Center (NESC, 2009)

- Independent review by EMU Tools Panel Configuration Control Board (Office, 2009)

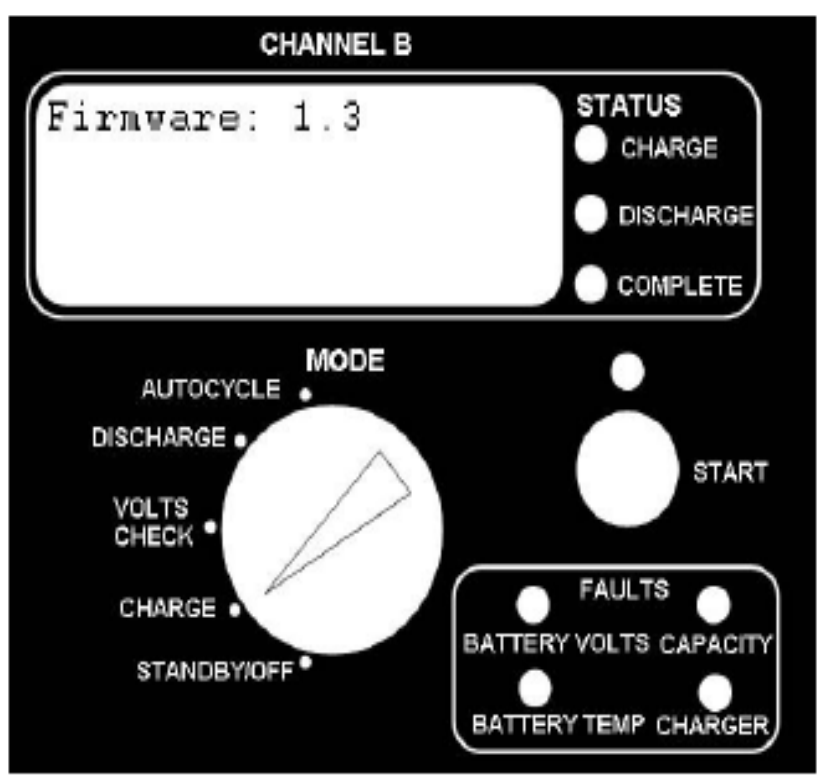

Figure 10. LIB Charger Front Panel User Interface

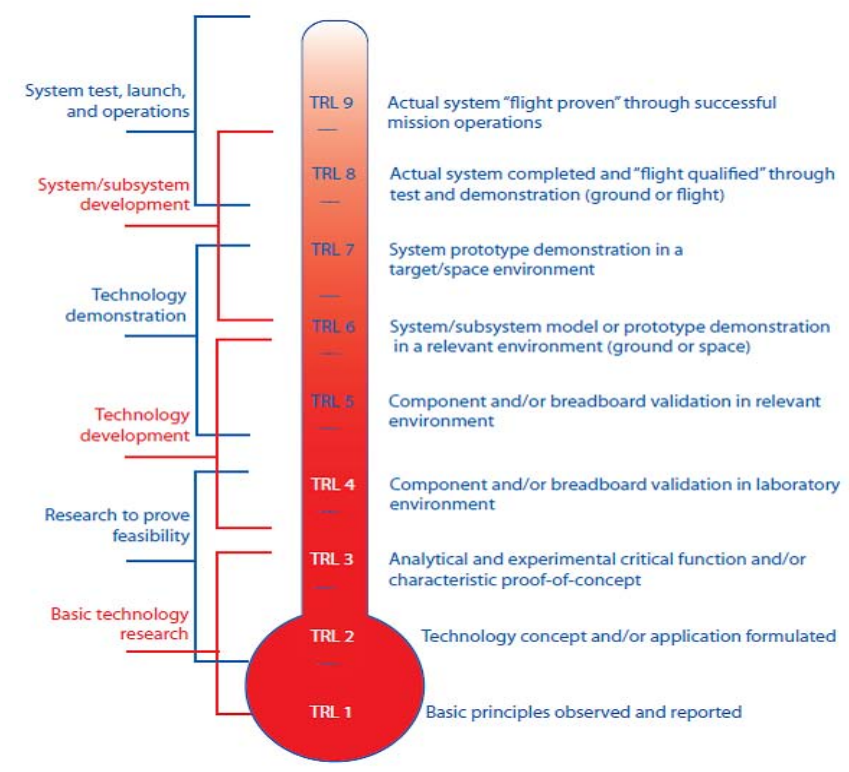

Figure 11. Technology Readiness Level 


\begin{tabular}{|c|l|}
\hline IRL & Definition [9] \\
\hline 7 & $\begin{array}{l}\text { The integration of technologies has been verified and validated with sufficient } \\
\text { detail to be actionable. }\end{array}$ \\
\hline 6 & $\begin{array}{l}\text { The integrating technologies can accept, translate, and structure information } \\
\text { for its intended application. }\end{array}$ \\
\hline 5 & $\begin{array}{l}\text { There is sufficient control between technologies necessary to establish, } \\
\text { manage, and terminate the integration. }\end{array}$ \\
\hline 4 & $\begin{array}{l}\text { There is sufficient detail in the quality and assurance of the integration between } \\
\text { technologies. }\end{array}$ \\
\hline 3 & $\begin{array}{l}\text { There is compatibility (i.e. common language) between technologies to orderly } \\
\text { and efficiently integrate and interact. }\end{array}$ \\
\hline 2 & $\begin{array}{l}\text { There is some level of specificity to characterize the interaction (i.e. ability to } \\
\text { influence) between technologies through their interface. }\end{array}$ \\
\hline 1 & $\begin{array}{l}\text { An interface (i.e. physical connection) between technologies has been identified } \\
\text { with sufficient detail to allow characterization of the relationship. }\end{array}$ \\
\hline
\end{tabular}

Fiqure 12. Inteqration Readiness Level

- Independent review by Hamilton Sundstrand Chief Engineers and Technical Managers ${ }^{5}$

The focus sessions and independent reviews provided rigorous insight into the extent of the internal short risk. As a result, the rigorous screening methodology presented previously was finalized and employed in the final battery design resulting in technology maturation to the delivery level. Integration readiness was achieved through partnering with the NASA EMU prime contractor and successful performance of the necessary demonstration tests utilizing high fidelity EMU equipment and simulated environments.

\section{Conclusion}

The Long Life Battery and Lithium Ion Battery Charger system design architecture, performance constraints and readiness maturation assessment are summarized herein. The Long Life Battery has consistently exceeded the minimum performance requirements as well as demonstrating tolerance to abusive conditions should the redundant engineered controls fail. The brief discussion regarding the maturity of technology readiness from TRL 6 to 8 is provided as is development of Integration Readiness from IRL 6 to IRL 8. Higher maturation level requires on-orbit performance which will not occur until the hardware is delivered to ISS as pressurized cargo in either the Space Transportation System or International Partner or Commercial cargo vehicle. Once on-orbit, the delivered system will remain functional for 5-10 years for the LLB and 15 years for the LIB Charger before replacement is necessary. A lifetime build of 20 LLBs and 8 LIB Chargers have been completed and 4 batteries and 2 chargers shipped for stowage on the next Shuttle logistic resupply mission. Deployment of this rechargeable power system will enable a reduced cost power option for future ISS EVA for years to come. Since the number of required EVA post-ISSassembly-complete is expected to diminish significantly from where they are today (and lithium ion is known to deliver more than the required capacity cycles), the long-term effect of quiescent storage is being assessed by parametric test of cells from the flight lot stored at multiple temperatures and states of charge. In addition to characterizing long term storage, a redundant charging method for long-term use on ISS is under development should the LIB Charger fleet suffer a systematic fault on-orbit. The LLB and LIB Charger system, and the corporate knowledge generated during development and design maturation, is well positioned to serve the ISS Program for years to come.

\section{Acknowledgments}

Thanks to the following organizations for their support on this effort: Denny Keys and the NESC Assessment Team

\footnotetext{
${ }^{5}$ Independent Review by Hamilton Sundstrand Engineering Manager, 2010 February
} 
Khandler Smith, Lawrence Chaney and Gi-Heon Kim of the National Renewable Energy Laboratory

Hamilton Sundstrand Corp

Science Application Internationl Corp (SAIC), NASA JSC Safety and Reliability

Symmetry Resources, Inc

ABSL Space Products

NASA JSC Engineering Directorate including the Avionics Engineering Division, Energy Systems Division, Energy Systems Test Area and Structural Engineering Division

Engineering and Science Contract Group, NASA JSC

\section{References}

EVA Office, J. S. (2003). JSC memo DX3-03-02. Houston.

NASA. (2007). Systems Engineering Handbook, NASA/SP-2007-6105 Rev1. NASA.

NESC. (2009). Assessment of Risks and Mitigation Strategies for the use of Lithium-Ion (Li-Ion) Long-Life Batteries (LLB), NESC PR-08-00492.

Office, E. (2009). Meeting Minutes, EVA Tools Panel Configuration Control Board. Houston.

Sauser, B., Ramirez-Marquez, J., Verma, D., \& Gove, R. (2006). Determining System Interoperability using an Integration Readiness Level. Stevens Institute of Technology, Systems Engineering and Engineering Management.

Smith, K. (2010). Thermal Analysis of the Vulnerability of the Spacesuit Battery Design to Short-Circuit Conditions," NREL/PR-540-47948. Manhattan Beach, CA, : 2010 Space Power Workshop.

Conference Proceedings. (2009). NASA Aerospace Battery Workshop. Huntsville, AL. 